\title{
Brief Communication: Earthquake-cloud coupling through the global atmospheric electric circuit
}

\author{
R. G. Harrison ${ }^{1}$, K. L. Aplin ${ }^{2}$, and M. J. Rycroft ${ }^{3}$ \\ ${ }^{1}$ Department of Meteorology, University of Reading, Earley Gate, Reading RG6 6BB, UK \\ ${ }^{2}$ Clarendon Laboratory, Denys Wilkinson Building, Keble Road, Oxford OX1 3RH, UK \\ ${ }^{3}$ CAESAR Consultancy, 35 Millington Road, Cambridge, CB3 9HW, UK, and Centre for Space, Atmospheric and Oceanic \\ Sciences, University of Bath, Bath BA2 7AY, UK
}

Correspondence to: K. L. Aplin (karen.aplin@physics.ox.ac.uk)

Received: 11 November 2013 - Published in Nat. Hazards Earth Syst. Sci. Discuss.: 6 December 2013

Revised: 14 March 2014 - Accepted: 19 March 2014 - Published: 10 April 2014

\begin{abstract}
We illustrate how coupling could occur between surface air and clouds via the global electric circuit through Atmospheric Lithosphere-Ionosphere Charge Exchange (ALICE) processes - in an attempt to develop a physical understanding of the possible relationships between earthquakes and clouds.
\end{abstract}

\section{Introduction}

From time to time, papers are published suggesting that there are visible changes in the atmosphere that are associated with earthquakes, or that could even provide an earthquake precursor. Because of the widespread availability of high-quality satellite imagery, such optical possibilities are clearly compelling. Recently, for example, Guangmeng and Jie (2013) considered the potential for using observations of cloud changes as an earthquake precursor, by examining sequences of satellite images around the times of earthquakes. A full statistical climatology of the cloud behaviour in any earthquake region is essential before any cloud feature can be truly regarded as anomalous, but, more importantly, a plausible physical mechanism able to connect earthquakes and clouds has also been lacking.

Generating a physical mechanism linking earthquakes and clouds is troublesome because there is no clear agreement on what constitutes an "earthquake cloud", and a wide range of disparate cloud-related phenomena have been attributed to the effects of earthquakes. For example, there are several reports of anomalous cloud formations over fault zones near earthquakes (e.g. Guangmeng and Jie, 2013; Guo and Wang, 2008), although the height of the clouds affected is not consistent. In some other cases the clouds described have been iridescent, implying that detailed droplet properties, such as size, might be affected by an underlying physical process. There are also observations of enhanced clear-sky emission in the thermal infrared radiation detected by satellites. Typically these are equivalent to a temperature change of a few Kelvin, beyond the natural variability (Tramutoli et al., 2005), appearing some days before the earthquake (e.g. Saraf et al., 2008; Guo and Wang, 2008).

At the simplest level, clouds require water vapour, which could be released from the Earth's crust by seismic changes. Whilst such plumes of water vapour might be initially buoyant from geothermal heating, mixing processes in the naturally variable lower atmosphere seem likely to remove the identity of the seismically generated water vapour (or water vapour fluctuations) as it ascends to cloud levels. (There is also little prospect of high-altitude clouds being affected in this way, such as those formed from ice). The thermal anomalies identified could also be generated by similar surface outgassing, such as the infra-red absorbing gases of carbon dioxide and methane (Saraf et al., 2008).

Changes in cloud features and associated thermal anomalies have been attributed to water condensation onto seismically-released ions (Pulinets and Ouzounov, 2011; Freund, 2013), which may exceed the existing natural background ionisation. A major difficulty with the ion-induced nucleation proposal is that condensation of water droplets on ions - a process exploited in the laboratory Wilson cloud 
chamber to visualise cosmic ray tracks - requires extreme levels of water super-saturation of $400 \%$ or more. This level of super-saturation is more than two orders of magnitude greater than that naturally occurring in the terrestrial atmosphere. Changes in ion properties through hydration have been reported, and nucleation to yield ultrafine particles has been observed, for example, in experiments using optimised gas mixtures (e.g. reviewed in Harrison and Carslaw, 2003). However, these molecular cluster ions or ultrafine particles remain much smaller than the minimum size of particle required for cloud droplet formation, which is typically a few hundred nanometers in diameter. Growth of ion clusters to these sizes in clean air with sufficient supply of condensable vapour requires many hours (e.g. Harrison and Carslaw, 2003). Hence, even if this growth process can occur without interruption in the real atmosphere where conditions are much more variable, the duration of the growth will allow the cluster ions concerned to be displaced by a considerable distance from their point of generation $(\sim 100 \mathrm{~km}$ for $10 \mathrm{~h}$, with a small surface wind speed of $3 \mathrm{~ms}^{-1}$ ). A rapid but continuous process, such as the flow of electric current, is therefore required if surface information is to be imprinted in clouds directly above seismic activity.

Changes in the surface structure of rocks under stress have also been suggested to lead to infra-red emission and subsequent thermal anomalies (Freund, 2013). Furthermore, seismically released atmospheric ions may themselves directly absorb infra-red radiation (e.g. Rycroft et al, 2012). Finally, a link between enhanced ionisation from radioactivity and clouds was suggested from the long-range cloud dissipation apparent in a satellite image of the Chernobyl reactor plume (Brandli and Leuck, 1987) ${ }^{1}$.

\section{Global circuit coupling}

An alternative route for earthquake coupling to clouds seems possible through atmospheric electricity. Previously, Harrison et al. (2010) argued that enhanced ionisation in the lower atmosphere (and, specifically, in the planetary boundary layer), will increase the vertical current flow always present in fair weather from the global atmospheric electric circuit (e.g. Rycroft et al., 2012). The importance of the vertical current density - denoted $J_{\mathrm{c}}$ - is that it links surface air ionisation changes directly to the ionosphere, unlike surface electric field changes, which are insufficient to cause ionospheric electrical changes (Denisenko et al., 2013). This mechanism of Atmospheric Lithosphere-Ionosphere Charge Exchange (subsequently referred to here by the acronym

\footnotetext{
${ }^{1}$ Ionospheric changes during two major nuclear reactor accidents are inconsistent. Fuks et al. (1997) observed an ionospheric response following the Chernobyl incident, but Kakinami et al. (2011) did not consider the ionospheric changes around the Fukushima event to be unambiguously linked with the nuclear accident.
}

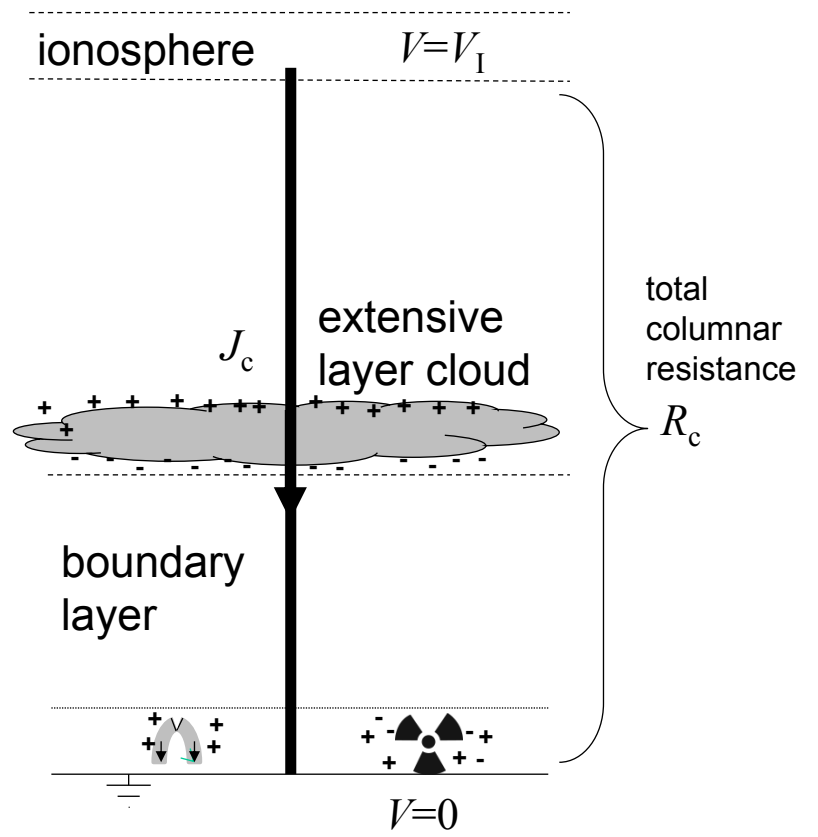

Fig. 1. Coupling of surface ionisation changes to layer clouds through the global circuit. The conduction current flowing (density $J_{\mathrm{c}}$ ) is related to the vertical columnar resistance $R_{\mathrm{c}}$ and the globally established ionospheric potential $V_{\mathrm{I}}$. The boundary layer in the base of the lower atmosphere contributes the majority of the columnar resistance. Hence, ionisation released into this region by rock fracturing (shown on the left) or radioactivity (shown on the right) will reduce $R_{\mathrm{c}}$ and increase $J_{\mathrm{c}}$ for fixed $V_{\mathrm{I}}$, from Ohm's Law. The charge accumulating on cloud droplets at the upper and lower cloud boundary is proportional to $J_{\mathrm{c}}$ and, therefore, in turn, to the surface ionisation. This charge may influence the cloud microphysical processes, e.g. via droplet interactions.

ALICE) provides an explanation for satellite observations of pre-earthquake changes in natural radio waves in nondisturbed weather. Encouraged by the agreement between the postulated changes and those now observed across a range of earthquakes (Piša et al., 2013), the ALICE mechanism is extended here to consider effects on simple cloud structures, horizontal layer clouds of water droplets (such as extensive low-level stratus clouds) in semi-fair weather, through which the vertical current must pass in overcast conditions.

The consequence of vertical current flow through the horizontal edge of a layer cloud is the local generation of charge at the horizontal cloud-air boundary (Fig. 1), which has already been directly observed within clouds using balloon-carried instrumentation (Nicoll and Harrison, 2010). Charging of the water drops at the upper and lower cloud boundaries is anticipated to influence, in some cases, the evaporation-condensation of drops, and also the collisional interactions between small droplets (Rycroft et al., 2012). These effects result from the charge obtained by the droplets after they have formed. The droplet charging is proportional to the vertical current flowing and the vertical gradient of the 
(a)

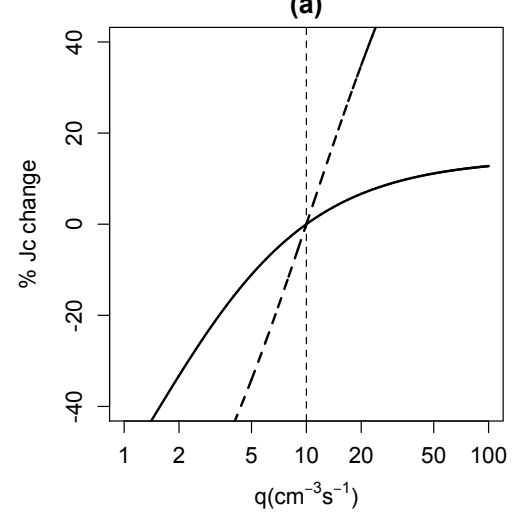

(b)

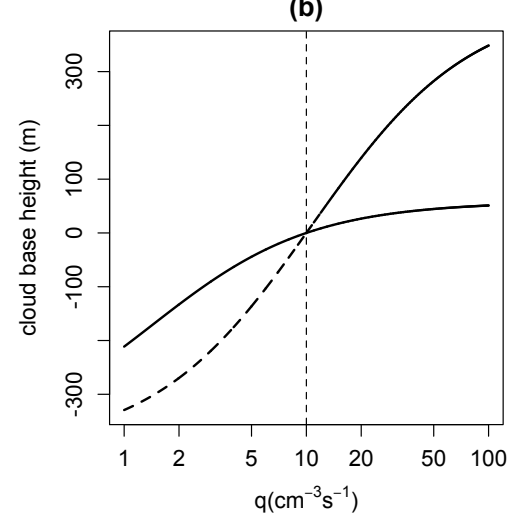

Fig. 2. Calculated response in atmospheric electric and cloud parameters to changes in the surface air volumetric ion production rate $q$ for low pollution air (solid lines) assuming 2000 particles $\mathrm{cm}^{-3}$ of radius $0.25 \mu \mathrm{m}$, and polluted air (dashed lines), assuming 15000 particles $\mathrm{cm}^{-3}$. Variations are shown for (a) the vertical conduction current $J_{\mathrm{c}}$ and (b) changes in the observed cloud base height.

cloud to clear air transition, with the charge per unit volume $\rho$ at the cloud boundary given by

$\rho=-\varepsilon_{0} J_{\mathrm{c}} \frac{\mathrm{d}}{\mathrm{d} z}\left(\frac{1}{\sigma}\right)$,

in which the conductivity $\sigma$ varies vertically with height $z$ across the horizontal cloud-air boundary, and $\varepsilon_{0}$ is the permittivity of free space.

Equation (1) shows that properties of the cloud - specifically, the charge per unit volume at the cloud edge - are linked to the vertical current flow. Should the current flow be modified by ionisation changes near the surface, such as through the release of radon or the fracture of rocks (e.g. Freund, 2013), the cloud droplet charge would also vary in response. The global circuit current therefore provides a link between surface changes and the cloud directly above.

\section{Quantitative considerations}

Changes in the vertical conduction current from surface ionisation variations can be calculated by considering the balance between ion generation and loss to atmospheric particles, for a unit area column of atmosphere. The full methodology was discussed in the description of the ALICE mechanism given in Harrison et al. (2010). For an ionospheric potential $V_{\mathrm{I}}$, which is assumed to be an equipotential region since the ionosphere's conductivity is many orders of magnitude greater than that of the air's conductivity below it, the conduction current density $J_{\mathrm{c}}$ is given by

$J_{\mathrm{c}}=\frac{V_{\mathrm{I}}}{R_{\mathrm{c}}} \approx V_{\mathrm{I}} /\left[\frac{k}{\sigma_{\mathrm{s}}}+R_{\mathrm{FT}}\right]$,

where $R_{\mathrm{c}}$ is the resistance of a unit area column between the surface and the ionosphere. This resistance can be estimated using an approximate model based on the total surface layer conductivity $\sigma_{\mathrm{s}}$, which is considered to represent the resistance in a layer of scale height $k$ ( $\sim 100$ to $500 \mathrm{~m})$ together with the resistance of the upper ("free troposphere") part of the columnar resistance $R_{\mathrm{FT}}$. The surface air conductivity $\sigma_{\mathrm{s}}$ depends on the concentration of small ions present $n$ and their mean mobility $\mu$, from

$\sigma_{\mathrm{s}}=2 n \mu e$,

where $e$ is the magnitude of the elementary charge (Harrison and Carslaw, 2003). The surface air conductivity can be determined in terms of the ion production rate $q$ and loss rate by ion-ion recombination and ion-aerosol attachment as

$\sigma_{\mathrm{s}}=\mu e \frac{\left[\sqrt{\left(\beta^{2} Z^{2}+4 \alpha q\right)}-\beta Z\right]}{\alpha}$,

where $\alpha$ is the ion-ion recombination coefficient $\left(1.6 \times 10^{-12} \mathrm{~m}^{3} \mathrm{~s}^{-1}\right), Z$ the monodisperse aerosol number concentration and $\beta$ the ion-aerosol attachment coefficient, which is $\sim 4 \times 10^{-11} \mathrm{~m}^{3} \mathrm{~s}^{-1}$ for $0.2 \mu \mathrm{m}$ radius aerosol. Harrison et al. (2010) also pointed out that the response depends on the background aerosol concentration. This is because the sensitivity of the vertical conduction current to surface ionisation change is greater in polluted air, as ion loss to aerosol particles is less effective at removing ions than, in clean air, the annihilation of ions by recombination of a positive ion with a negative ion.

It can be seen from Eq. (4) that the air conductivity varies with the ion production rate $q$, and that, through Eq. (2), the conduction current will respond, leading, through Eq. (1), to a change in the cloud edge charge. Hence a long-range relationship exists between the surface ion production and the cloud properties.

Calculation of the sensitivity of the vertical conduction current requires some estimate of the likely changes in the ionisation rate associated with earthquakes, from both radon 
Table 1. Summary and quantitative estimates of mechanisms by which rock stresses can produce excess ionisation in surface air before earthquakes.

\begin{tabular}{|c|c|c|}
\hline Mechanism, example & Ionisation changes & Reference \\
\hline $\begin{array}{l}\text { Radon emission } \\
\text { before } 1995 \text { Kobe } \\
\text { earthquake }\end{array}$ & $\begin{array}{l}\text { Radon increase measured, conservatively estimated at } 10 \mathrm{~Bq} \mathrm{~m}^{-3} \text {. Ion balance equation } \\
\text { used to infer a } 40 \% \text { change in ion concentration. Measured increases in ion concentra- } \\
\text { tion before the earthquake of } 1000-1400 \mathrm{~cm}^{-3} \text { were consistent with changes inferred } \\
\text { from the radon data. This implies a change in volumetric ionisation rate of } 40-100 \% \text {, } \\
\text { i.e. a rate of } 14-20 \mathrm{~cm}^{-3} \mathrm{~s}^{-1} \text {. }\end{array}$ & $\begin{array}{l}\text { Omori et al. (2007) and } \\
\text { references therein } \\
\text { Yasuoka et al. (2010) and } \\
\text { references therein }\end{array}$ \\
\hline $\begin{array}{l}\text { Radon emission in general } \\
\text { before earthquakes }\end{array}$ & Volumetric ionisation rate $=100-10000 \mathrm{~cm}^{-3} \mathrm{~s}^{-1}$ & Liperovsky et al. (2005) \\
\hline $\begin{array}{l}\text { Fractoemission during } \\
\text { earthquakes and } \\
\text { volcanic eruptions }\end{array}$ & $\begin{array}{l}\text { Ions per unit area at rock surface given as } 10^{9} \mathrm{~cm}^{-2} \mathrm{~s}^{-1} \text {; vertical dimension of region } \\
\text { into which the ions were released not available }\end{array}$ & Freund (2013) \\
\hline
\end{tabular}

release and fractoemission (Table 1). Measurements of ionisation rate anomalies before earthquakes are sparse and it is difficult to trace some of the quoted figures to reliable measurements. Nevertheless, there are good data available from the time of the Kobe earthquake in Japan in 1995 (e.g. Yasuoka et al., 2010), where radon concentrations increased for about 2 months before the earthquake, reaching a peak (at well over three standard deviations above the previous background) 17 days before the earthquake, which was sustained until the earthquake. When electricity supplies to the instruments resumed after the earthquake, radon levels had returned to the previous background level. Based on the radon increase of $10 \mathrm{Bqm}^{-3}$, and concurrent ion measurements, Omori et al. (2007) estimated a $40 \%$ change in ion concentration. In aerosol-free air, the ion concentration is proportional to the square root of the ion production rate and, in polluted urban air, the ion concentration scales linearly with the ionisation rate (e.g. Harrison and Carslaw, 2003). The enhanced radon concentrations observed therefore correspond to a change in the ion production rate of $40-100 \%$, i.e. $q=14-20 \mathrm{~cm}^{-3} \mathrm{~s}^{-1}$, assuming a background ionisation rate of $q=10 \mathrm{~cm}^{-3} \mathrm{~s}^{-1}$.

These values of $q$ are relatively conservative when compared to other suggested values, but they are based on field measurements rather than models. (Liperovsky et al. (2005) estimate a much greater ionisation rate enhancement, of 100$10000 \mathrm{~cm}^{-3} \mathrm{~s}^{-1}$.) Fractoemission mechanisms proposed by Freund (2013) do not yet provide an adequate estimate of the volumetric ionisation rate, so a combination of the radon-enhanced ionisation rates presented in Table 1 has been used to estimate the enhanced ionisation rate as up to $100 \mathrm{~cm}^{-3} \mathrm{~s}^{-1}$.

\section{Estimate of cloud response}

Some indications of the modulation of cloud properties which might be expected from conduction current changes are available from studies of polar night clouds, showing an averaged response in the cloud base consistent with conduction current variations (Harrison and Ambaum, 2013). Polar night clouds were chosen for this analysis to remove the usual dominating influence of diurnal variations from solar heating, and the response was observed in the cloud base height. The determination of cloud base height is essentially a measurement of vertical visibility, which can be regarded as indicating a change in the cloud base droplet properties, such as droplet size or concentration. In this study, which averaged the polar night cloud base measurements made, a similar response was found for both the Arctic and Antarctic of about $4 \mathrm{~m}$ change in cloud base height for a unit percentage change in the conduction current density.

If this sensitivity is appropriate to semi-fair weather layer clouds in general (and a similar sensitivity was found through an entirely different approach at a mid-latitude continental site by Harrison et al., 2013), then the possible cloud response to earthquake-induced changes can be estimated in similar terms. Figure $2 \mathrm{~b}$ applies this response to the calculations of current density change from ionisation, obtained from Fig. 2a. The sensitivity of the change in cloud properties is, as expected, greater in the polluted case, although it must be emphasised this is a highly idealised calculation which neglects any additional interactions between the cloud and pollution and indeed any other sources of variability. However, it still serves to illustrate the potential link between surface ionisation changes and cloud properties aloft.

\section{Conclusions}

In reality, there is always considerable variability present in the atmosphere and in clouds. Consequently there are many competing sources of cloud variability, such as that associated with local orography, which may obscure effects solely resulting from surface ionisation changes. Nevertheless, there may also be conditions in which a cloud response is observable, or indeed has possibly already been observed. Our purpose here is merely to suggest that there is a possible 
physical mechanism which can provide earthquake-cloud coupling based on the ALICE ideas presented previously, which should be explored further. An appealing feature of this mechanism is that, rather than requiring transport of the surface ionisation up to the cloud despite appreciable ion loss processes (with uncertain or indeed unlikely responses in the cloud properties), the global circuit conduction current directly, and rapidly, connects surface air ionisation changes to the properties of the cloud above in semi-fair weather. Many details clearly remain to be worked out, which we hope can be achieved experimentally and theoretically despite the traditional discipline boundaries between atmospheric and Earth sciences.

Edited by: A. Costa

Reviewed by: two anonymous referees

\section{References}

Brandli, H. W. and Leuck, D.: Nuclear summer, Satellite, 12, 23-24, 1987.

Denisenko, V. V., Ampferer, M., Pomozov, E. V., Kitaev, A. V., Hausleitner, W., Stangl, G., and Biernat, H. K.: On electric field penetration from ground into the ionosphere, J. Atmos. Sol.-Terr. Phys., 102, 341-353, 2013.

Freund, F.: Earthquake Forewarning - A Multidisciplinary Challenge from the Ground up to Space, Acta Geophys., 61, 775-807, 2013.

Fuks, I. M., Shubova, R. S., and Martynenko, S. I.: Lower ionosphere response to conductivity variations of the near-earth atmosphere, J. Atmos. Sol.-Terr Phys., 59, 961-965, 1997.

Guangmeng, G. and Jie, Y.: Three attempts of earthquake prediction with satellite cloud images, Nat. Hazards Earth Syst. Sci., 13, 91-95, doi:10.5194/nhess-13-91-2013, 2013.

Guo, G., and Wang, B.: Cloud anomaly before Iran earthquake, Internat. J. Remote Sens., 29, 1921-1928, 2008.

Harrison, R. G. and Ambaum, M. H. P.: Electrical signature in polar night cloud base variations, Environ. Res. Lett., 8, 015027 , doi:10.1088/1748-9326/8/1/015027, 2013.

Harrison, R. G. and Carslaw, K. S.: Ion-aerosol-cloud processes in the lower atmosphere, Rev. Geophys., 41, 1012, doi:10.1029/2002RG000114, 2003.

Harrison, R. G., Aplin, K. L., and Rycroft, M. J.: Atmospheric electricity coupling between earthquake regions and the ionosphere, J. Atmos. Sol.-Terr. Phys., 72, 376-381, 2010.
Harrison, R. G., Nicoll, K. A., and McWilliams, K. A.: Space weather driven changes in lower atmosphere phenomena, J.Atmos. Sol.-Terr. Phys., 98, 22-30, 2013.

Kakinami, Y., Masashi, K., Liu, J. Y., Watanabe, S., and Mogi, T.: Ionospheric disturbance associated with radiation accidents of Fukushima I nuclear power plant damaged by the M9.0 2011 Tohoku Earthquake, Adv. Space Res., 48, 1613-1616, 2011.

Liperovsky, V. A., Meister, C.-V., Liperovskaya, E. V., Davidov, V. F., and Bogdanov, V. V.: On the possible influence of radon and aerosol injection on the atmosphere and ionosphere before earthquakes, Nat. Hazards Earth Syst. Sci., 5, 783-789, doi:10.5194/nhess-5-783-2005, 2005.

Nicoll, K. A. and Harrison, R. G.: Experimental determination of layer cloud edge charging from cosmic ray ionisation, Geophys. Res. Lett., 37, L13802, doi:10.1029/2010GL043605, 2010.

Omori, Y., Nagahama, H., Kawada, Y., Yasuoka, Y., Ishikawa, T., Tokonami, S., and Shinogi, M.: Preseismic alteration of atmospheric electrical conditions due to anomalous radon emanation, Phys. Chem. Earth, 34, 435-440, 2009.

Piša, D., Němec, F., Santolik, O., Parrot, M., and Rycroft, M.: Additional attenuation of natural VLF electromagnetic waves observed by the DEMETER spacecraft resulting from preseismic activity, J. Geophys. Res. Space Phys., 118, 5286-5295, doi:10.1002/jgra.50469, 2009.

Pulinets, S. and Ouzounov, D.: Lithosphere-atmosphere-ionosphere coupling (LAIC) model - an unified concept for earthquake precursors validation, J. Asian Earth Sci., 41, 371-382, 2011.

Rycroft, M. J., Nicoll, K. A., Aplin, K. L., and Harrison, R. G.: Recent advances in global electric circuit coupling between the space environment and the troposphere, J. Atmos. Sol.-Terr. Phys., 90/91, 198-211, 2012.

Saraf, A. K., Rawat, V., Banerjee, P., Choudhury, S., Panda, S. K., Dasgupta, S., and Das, J. D.:, Satellite detection of earthquake thermal infrared precursors in Iran, Natural Hazards, 47, 119135, 2008.

Tramutoli, V., Cuomo, V., Filizzola, C., Pergola, N., and Pietrapertosa, C.: Assessing the potential of thermal infrared satellite surveys for monitoring seismically active areas: The case of Kocaeli (Izmit) earthquake, August 17, 1999, Remote Sens. Environ., 96, 409-426, 2005.

Yasuoka, Y., Nagahama, H., and Ishikawa, T. (Eds): Anomalous Radon Concentration prior to an earthquake: a case study on the 1995 Kobe Earthquake, Japan (Collected Papers), Lambert Academic Publishing, Saarbrucken, 2010. 